\title{
ASSISTENACIA DE ENFERMAGEM A PACIENTE COM COMPORTAMENTO ANTI-SOCIAL COMO MANIFESTAÇÃO DE PERSONALIDADE PSICOPÁTICA
}

\author{
Marina Borges Teixeira* \\ Maguida Costa Stefanelli* \\ Evalda Cançado Arantes **
}

TEIXEIRA, M. B.; STEFANELLI, M. C.; ARANTES, E. C. Assistência de enfermagem a paciente com comportamento anti-social como manifestação de personalidade psicopática. Rev. Esc. Enf. USP, São Paulo, 13(3):261-266, 1979.

As autoras tecem considerações sobre assistência de enfermagem a paciente com comportamento anti-social quando este comportamento é evidência de manifestação de distúrbio da personalidade (personalidade psicopática).

\section{INTRODUÇÃO}

Nas interações com pessoas que trabalham em clinica psiquiátrica, percebe-se atitude negativa com .relação ao paciente com diagnóstico de personalidade psicopática. Há uma descrença geral na recuperação deste paciente e essa descrença tem tido influência na assistência de enfermagem, segundo já se pôde observar na prática diária. SCHNEIDER ${ }^{6}$ comenta que, após a pessoa ser rotulada de personalidade psicopática, é mergulhada em fatalismo, parecendo que nda mai shá a fazer por ela.

É necessário lembrar que nem toda pessoa com personalidade psicopática exibe comportamento anti-social. Ao mesmo tempo, nem todo individuo que apresenta comportamento anti-social pode ser rotulado como personalidade psicopática. Há pacientes que manifestam comportamento anti-social em decorrência de sintomas psicóticos de vários quadros clínicos, entre outros, o esquizofrênico, o oligofrênico, o epiléptico, o paciente na fase de mania da psicose maníaco-depressiva.

Uma pessoa com personalidade psicopática, com manifestação de comportamento anti-social, raramente procura assistência psiquiátrica voluntariamente. Ela só é trazida ao hospital quando apresenta outros problemas ou distúrbios mentais associados como toxicomanias, alcoolismo, perversões sexuais ou outras manifestaรõos que evidenciam um quadro psicótico. Em geral são trazidas ao hospital quando seu comportamento não é mais tolerado pela família ou pela comunidade.

O conceito de personalidade psicopática é amplamente discutido entre os autores. Não só o conceito como o próprio termo (PASTERNACK ${ }^{4}$, CLEKLEY $^{1}$ e FREEDMAN et alii $^{2}$ ).

Segundo SCHNEIDER ${ }^{6}$, personalidade psicopática é aquela que sofre por sua anormalidade e devido a ela faz a sociedade sofrer; sofre pela própria anomalia da personalidade. Ressalta o autor que este conceito é baseado em razões práticas.

- Professor Assistente da disciplina Enfermagem Psiquíatrica da EEUSP. Mestre em Enfermagem.

-* Professor Assistente Doutor da disciplina Enfermagem Psiquiátrica da EEUSP. 
A classificação de SCHNEIDER ${ }^{6}$ das personalidades psicopáticas corrobora a idéia de que nem todas as pessoas com personalidade psicopática apresentam comportamento anti-social. Ele as classifica em: hipertímicas, depressivas, inseguras de si mesmas, fanáticas, necessitadas de estima, lábeis de humor, explosivas, desalmadas, abúlicas e astênicas. Sabemos que nenhuma das classificações está isenta de críticas, mas a de SCHNEIDER ${ }^{6}$ é a que tem maior aceitação em nosso meio e também na Europa, segundo SANTO-DOMINGO CARRASCO ${ }^{5}$. Há várias outras classificações, entre elas a de HERRERA-LUQUE ${ }^{3}$.

SANTO-DOMINGO CARRASCO ${ }^{5}$ considera a pessoa com personalidade psicopática como aquela que desde a infância vê-se envolvida em atos não aceitos socialmente e que trazem complicações com forte expressão social para a vida familiar.

FREEDMAN et alii ${ }^{2}$ transcrevem o conceito de personalidade psicopática da American Psychiatric Association's Diagnostic and Statistical Manual of Mental Disorders (DSM-II). Segundo esta Associação, o termo personalidade anti-social é reservado para individuos não socializáveis basicamente, cujas manifestações de comportamento os colocam freqüentemente em conflito com a sociedade; são incapazes de um sentimento de lealdade para com indivíduos, grupo e sociedade. PASTERNACK ${ }^{4}$ apresenta conceito semelhante.

Outro aspecto controvertido é o nível de inteligência de pessoa com personalidade psicopática. Há uma tendência, entre os que trabalham com este tipo de paciente, em julgá-lo supra-dotado intelectualmente. HERRERA-LUQUE ${ }^{3}$ apresenta-nos o resultado do estudo de duzentas pessoas com personalidade psicopática, das quais $27 \%$ tinha nível de inteligência igual à média da população, $32 \%$ abaixo e $41 \%$ acima, o que parece fazer cair por terra o conceito que reina entre os leigos, e mesmo entre alguns elementos da área da Psiquiatria, de que toda pessoa com personalidade psicopática é supra-dotada intelectualmente.

\section{Caracterização da personalidade psicopática}

Dadas as alterações das esferas psíquicas instintivas e afetivas, as manifestações de comportamento que podemos observar no indivíduo com personalidade psicopática com comportamento anti-social são bem características.

$E$ individuo que vive apenas o momento presente, sem se preocupar com as ações do passado ou com que possa acontecer no futuro.

É instável, tanto no plano profissional como no social. Não para em empregos, não assume responsabilidade. Alguns, como os abúlicos, nem chegam a trabalhar. $\mathrm{O}$ que apresenta comportamento anti-social é como que dotado de um encanto superficial que o ajuda a relacionar-se facilmente com as pessoas, mas é incapaz de uma relação mais profunda. Aproveita-se deste encanto superficial para manipular as pessoas que o rodeia, a fim de obter ganhos na satisfação de seu próprio interesse. Pode chegar até à tentativa de sedução, visando única e exclusivamente a realização de objetivos momentâneos.

Esse paciente raramente aparece como culpado dos atos anti-sociais que promove. Justifica todos os seus atos com argumentos lógicos e parece não se arrepender do que faz. 
Se a pessoa que manifesta comportamento anti-social, num determinado momento, recebe punição devido a manifestação de comportamento inadequada, repete esta mesma manifestação um sem número de vezes, parecendo não se preocupar com as conseqüências.

Em geral ele não se acha doente e não aceita sua internação, mas não faz disso um drama.

Não aceita autoridade, padrões éticos, regras sociais e morais, sendo visto como inadaptado.

De acordo com a literatura, podemos resumir as características gerais do comportamento de um paciente com personalidade psicopática com manifestações antisociais em:

- desproporção entre estímulo e reação;

— intolerância aos estímulos desagradáveis;

- incapacidade de viver além do momento presente;

- racionalização dos atos praticados;

— instabilidade instinto-afetiva;

- incapacidade de aprender com a experiência;

- ausência de remorso ou culpa pelos atos praticados;

- egocentrismo cxagerado;

- relacionamento interpessoal superficial e

- tendência ao comportamento mitômano-fantástico.

A pessoa com personalidade psicopática que apresenta comportamento antisocial, em geral, o manifesta provocando tumultos, motins, brigas, roubo, incêndio, tentando homicídio, suicídio, usando tóxico, manifestando perversão sexual ou por qualquer outro ato anti-social.

\section{Assistência de enfermagem}

Paciente com personalidade psicopática e comportamento anti-social raramente é encontrado em clínica psiquiátrica. Em geral só é internado quando apresenta algum distúrbio mental associado.

A atitude da enfcrmeira com este paciente é fundamental para a eficiência ou não da assistência de enfermagem. A descrença e o fatalismo que existem em relação a este paciente levam, em geral, a enfermeira a apresentar atitude negativa para com ele. Contribui, também, para a formação desta atitude negativa o fato do próprio paciente não se considerar doente e conseqüentemente não aceitar a internação e o tratamento. A esses problemas, que são decorrentes das características de paciente com o comportamento em foco, temos que acrescentar a incapacidade de aceitar as normas e rotinas hospitalares, comportamento que o leva a sentir a rejeição do grupo. 
A enfermeira só será capaz de ajudar efetivamente o paciente após superar seus próprios problemas em relação ao comportamento dele. Como conseqüência da sua atitude negativa em relação ao paciente surge a sua não aceitação dessa pessoa como doente e de sua internação em hospital psiquiátrico, o que dificulta $\mathrm{cm}$ muito a assistência de enfermagem. Ela precisa controlar sua ansiedade, irritação, falta de confiança e rejeição pelo paciente. A falta de respeito aos limites impostos e à formação de grupo com outros pacientes com comportamento semelhante ou sugestionáveis são dificuldades também a enfrentar.

Outro problema para o qual a enfermeira tem de estar atenta é o envolvimento emocional não terapêutico comum no relacionamento com estes pacientes, quando desenvolvido sem supervisão, pois a manipulação é uma constante no comportamento deste paciente, juntamente com o teste aos limites impostos e à capacidade profissional da cnfermeira.

A enfermeira, ao prestar a assistência a este paciente, deverá primeiramente analisar sua própria atitude, seus sentimentos e reações em face das manifestações do comportamento dele. Só após conseguir vencer suas idéias pré-concebidas, em relação a um paciente com personalidade psicopática, com comportamento antisocial, é que ela poderá sentir interesse autêntico pelo paciente como pessoa e ajudá-lo a desenvolver padrões de comportamento socialmente aceitáveis.

As normas e rotinas do hospital devem ser explicadas ao paciente; a enfermeira deixará clara a importância das mesmas, a necessidade delas serem cumpridas e o que espera dele. Em geral, esse paciente testa essas normas e rotinas, provocando ansiedade e irritação na enfermeira. Se ela não estiver preparada para enfrentar as frustrações que essas manifestações de comportamento acarretam, sentir-se-á invadida por um sentimento de impotência quanto ao paciente, o que poderá levá-la a rejeitá-lo abertamente.

O paciente, para a consecução de seus objetivos, manipula não só a enfermeira como as demais pessoas ao seu redor. A habilidade dele é tal que, muitas vezes, não é percebida. A pessoa manipulada é, então, envolvida e passa a atuar de forma não terapêutica, podendo inclusive questionar a internação do paciente. Daí a importância da enfermeira analisar constante e objetivamente a sua atuação, para evitar que ocorra esta situação ou, pior ainda, reação de raiva de sua parte, de rejeição, e, às vezes, de agressividade, quando percebe que foi manipulada e que seu envolvimento emocional não terapêutico a impediu de atuar profissionalmente. $O$ paciente pode, até valer-se de seu encanto superficial e fluência no falar para chegar à tentativa de sedução da enfermeira.

Quando o paciente apresenta manifestações de comportamento anti-social a enfermeira deverá colocar limites a esse comportamento. Uma vez impostos, os limites deverão ser obedecidos. Se a enfermeira não estiver atenta para este fato, ela perderá o controle da situação na Unidade e dificilmente conseguirá manter seu papel profissional. Esses limites ao comportamento do paciente devem ser colocados de forma clara, tanto para ele como para os demais membros da equipe. Tato e firmeza são necessários nesta colocação, para que a situação não provoque maior hostilidade por parte do paciente. Freqüentemente o paciente testa estes limites. A enfermeira precisa esta ciente de que está sendo testada e controlar sua ansiedade e irritação, mantendo os limites impostos e usando sua autoridade 
racionalmente, em benefício do paciente. Quando ela percebe que não é capaz de atuar terapeuticamene por mais tempo, deve recorrer à ajuda de um profissional mais experiente e, se necessário, afastar-se o tempo mínimo possível para a recuperação do seu controle emocional.

Quando surge na unidade uma situação que requer imposição de limites, a enfermeira deve ser capaz de reconhecer o responsável pela situação a fim de não cometer injustiça em relação aos outros pacientes. Isso porque o paciente com personalidade psicopática, com manifestações de comportamento anti-social, raramente aparece como responsável pelas situações desagradáveis que provoca. Como uma das características deste comportamento é "não aprender com a experiência", punições não atingem o efeito terapêutico desejado. $O$ ideal então é fazer um plano de atividade diária para o paciente, de preferência elaborado com ele. Isto canalizará sua atenção. A expectativa de participação do paciente neste plano, por parte da enfermeira, deverá transmitir-lhe a necessidade de corresponder a esta esperança, estimulando-o assim, a desenvolver senso de responsabilidade para com as tarefas assumidas. Uma vez que o paciente tenha aceitado o plano de atividade e tomado o compromisso, de executá-lo, isto deve ser observado. É importante valorizar a participação do paciente, quando adequada.

A enfermeira deve evitar que este paciente forme grupos com outros que tenham as mesmas características de comportamento (toxicômanos, alcoolistas, perversos sexuais) e com aqueles facilmente manipuláveis (oligofrênicos, pacientes sob efeito de drogas neurolépticas e neuróticos). Com estes ele pode organizar fugas, motins, roubo, tentativas de homicídio e de perversões sexuais. Vigilância constante e discreta deverá ser mantida por todos os elementos da equipe. Esse aspecto da assistência de enfermagem deve ser observado também na escolha de grupos para atividades. Quando o paciente estiver em grupo, a enfermeira deverá supervisionálo para evitar que exerça liderança prejudicial sobre os outros e que não dê oportunidade a estes de se manifestarem. Essas medidas visam a manutenção do clima terapêutico da Unidade, a proteção do paciente e dos demais, e evitar a necessidade de sua transferência para outra Unidade.

Paciente com esse comportamento provoca desgaste emocional muito intenso da enfermeira. Por isso não é aconselhável que a assistência de enfermagem a este seja prestada por enfermeiras principiantes ou estudante de enfermagem. Mesmo quando a assistência deste é realizada por enfermeira competente, há a necessidade de que seja prestada sob supervisão. Essa supervisão pode ser feita por uma colega mais experiente que atue no mesmo campo. Quando não é possível contar com uma colega deve a enfermeira recorrer ao psiquiatra. Qualquer destes elementos, que não está envolvido com o paciente, é capaz de perceber quando ele está testando ou manipulando a enfermeira sem que esta perceba e é capaz de avaliar objetivamente o envolvimento emocional da enfermeira com o paciente e de não permitir que este ultrapasse o limite terapêutico. A enfermeira que estabelece relacionamento terapêutico com esse paciente deve expressar abertamente seus sentimentos durante a conferência de supervisão e analisá-los realisticamente, pois a repressão destes será prejudicial à assistência do paciente.

Para que os objetivos do plano de assistência sejam atingidos é necessário que a enfermeira seja capaz de transmitir a todos da equipe a sua atitude positiva, le- 
vando-os a desenvolver interesse pelo paciente como ser humano, necessitado de ajuda, e que todos tenham a mesma linha de ação com o paciente.

TEIXEIRA, M. B.; STEFANELLI, M. C.; ARANTES, E. C. Nursing care of patients with antisocial behavior as manifestation of personality disorder. Rev. Esc. Enf. USP, São Paulo, 13(3):261-266, 1979.

The authors discuss how nursing personnel should deal with patients who suffer from personality disorders when they show signs of antisocial behavior.

\section{REFERENCIAS BIBLIOGRAFICAS}

1. CLECKLEY, H. The mask of sanity. 5. ed. Saint Louis, Mosby, 1976. p. 10-7.

2. FREEDMAN, A. M. et alli. Personality disorders. In: Modern synopsis of comprehensive textbook of psiquiatry II. Baltimore, Williams \& Wilkins, 1976. cap. 21, p. 644-52.

3. HERRERA-LUQUE, F. Las personalidades psicopáticas. 2. ed. Barcelona, Científico-Médica, 1970. p. 13.7 e 85.90.

4. PASTERNACK, S. A. Las personalidades explosiva, antisocial-y pasiva-agresiva. In: LION, J. R. Transtornos de personalidad. Barcelona, Salvat, 1978. cap. 4, p. 50-70.

5. SANTO-DOMINGO CARRASCO, J. Personalidades anormales y psicopatas. In: Elementos de psiquiatría y assistencia psiquiátrica. Barcelona, Cientifico-Médica, 1968. cap. 16, p. 187.93.

6. SCHNEIDER, K. Las personalidades psicopáticas. Madrid, Morata, 1971. 214 p. 